\title{
BMJ
}

\section{Alcohol consumption and alcohol counselling behaviour among US medical students: cohort study}

\author{
Erica Frank, professor and Canada research chair, professor and senior adviser, ${ }^{1,2}$ Lisa Elon, senior \\ associate faculty, ${ }^{3}$ Timothy Naimi, medical epidemiologist, ${ }^{4}$ Robert Brewer, medical epidemiologist ${ }^{4}$
}

'University of British Columbia, School of Population and Public Health, and Department of Family Practice, 5804 Fairview Avenue, Vancouver, BC, Canada

${ }^{2}$ Emory University School of Medicine, Department of Family and Preventive Medicine, 49 Jesse Hill Jr Drive, Atlanta, GA 30303, USA

${ }^{3}$ Emory University Rollins School of Public Health, Department of Biostatistics and Bioinformatics, 1518 Clifton Road, Atlanta, GA 30322

${ }^{4}$ National Center for Chronic Disease Prevention and Health Promotion, Centers for Disease Control and Prevention, Mail stop k-67, 4770 Buford Highway NE, Atlanta, GA 30341

Correspondence to: $\mathrm{E}$ Frank efrank@emory.edu

Cite this as: BMJ 2008;337:a2155 doi:10.1136/bmj.a2155

\section{ABSTRACT}

Objective To determine which factors affect alcohol counselling practices among medical students.

Design Cohort study.

Setting Nationally representative medical schools $(n=16)$ in the United States.

Participants Medical students who graduated in 2003.

Interventions Questionnaires were completed (response rate $83 \%$ ) at the start of students' first year ( $n=1846$ / 2080), entrance to wards (typically during the third year of training) ( $n=1630 / 1982)$, and their final (fourth) year $(n=1469 / 1901)$.

Main outcome measures Previously validated questions on alcohol consumption and counselling.

Results $78 \%$ (3777/4847) of medical students reported drinking in the past month, and a third (1668/4847) drank excessively; these proportions changed little over time. The proportion of those who believed alcohol counselling was highly relevant to care of patients was higher at entrance to wards $(61 \% ; 919 / 1516)$ than in final year students (46\%; 606/1329). Although students intending to enter primary care were more likely to believe alcohol counselling was highly relevant, only $28 \%$ of final year students $(391 / 1393)$ reported usually or always talking to their general medical patients about their alcohol consumption. Excessive drinkers were somewhat less likely than others to counsel patients or to think it relevant to do so. In multivariate models, extensive training in alcohol counselling doubled the frequency of reporting that alcohol counselling would be clinically relevant (odds ratio $2.3,95 \%$ confidence interval 1.6 to 3.3 ) and of reporting doing counselling $(2.2,1.5$ to 3.3$)$.

Conclusions Excessive drinking and binge drinking among US medical students is common, though somewhat less prevalent than among comparably aged adults in the US general population. Few students usually discussed alcohol use with patients, but greater training and confidence about alcohol counselling predicted both practising and believing in the relevance of alcohol counselling. Medical schools should consider routinely training students to screen and counsel patients for alcohol misuse and consider discouraging excessive drinking.

\section{INTRODUCTION}

Each year, excessive alcohol consumption kills about 79000 people in the United States, ${ }^{1}$ making it the third leading preventable cause of death. ${ }^{2}$ Clinical alcohol screening and brief counselling help to reduce excessive consumption and related harms and are therefore recommended by the US Preventive Services Task Force. ${ }^{3}$ Such counselling is among the most effective and cost effective clinical preventive services. ${ }^{4}$ In the US, however, few health providers ask patients about their alcohol use,${ }^{56}$ despite about $75 \%$ of excessive drinkers having current health insurance and reporting having a check up within the past 24 months. ${ }^{7}$ While several factors contribute to low counselling rates, many physicians are unaware of guidelines for low risk drinking and harmful levels of alcohol consumption, and many feel ill prepared to counsel their patients. ${ }^{8}$ It is not clear how medical students' experiences and drinking behaviours might relate to their opinions or subsequent practices.

Drinking behaviours among medical students have important implications for the health of the general population. Firstly, physicians and future physicians are important opinion leaders and role models in terms of health related behaviours. Secondly, medical students' own drinking behaviours might shape their beliefs about levels of consumption that are normal or safe, particularly in the absence of specific knowledge about evidence based drinking guidelines. Finally, the drinking behaviours of medical students might influence their attitudes and comfort about counselling those who drink excessively; there is a strong and consistent relation between physicians' personal health practices and their counselling practices, ${ }^{9}$ including their practices around alcohol. ${ }^{10}$ Understanding any association between medical students' alcohol counselling habits and their drinking patterns and educational experiences could help increase screening and brief counselling interventions among healthcare providers.

We investigated the drinking habits of medical students and any association between these habits and personal, professional, and school based characteristics. We also examined whether a belief that alcohol counselling was highly relevant to intended specialty and self reported frequency of alcohol 
counselling were associated with variables that could be influenced in medical school.

\section{DESIGN}

\section{Study design}

All medical students graduating in 2003 at 16 US medical schools were eligible to complete three questionnaires during their medical training: at first year orientation (summer/autumn 1999), entrance to wards (typically in their third year), and in their final year.

A convenience sample of 17 US medical schools participated in the study; one school was excluded for non-adherence to the protocol. The 16 remaining schools were relatively representative of all US medical schools in terms of student age (first year student average age $24 v 24$ nationally), school size (students per school 563 v 527 nationally), medical school research ranking from the US National Institutes of Health (school average $64 v 62$ nationally), private/public school balance (51\% private schools $v 41 \%$ nationally), underrepresented minorities (13\% black, Hispanic, and Native American $v 11 \%$ nationally), sex (45\% women $v 43 \%$ nationally), and geographical distribution. ${ }^{11-14}$

Students' responses were linked across time with a unique identifier consisting of mother's initials at her birth and father's first two initials. At entry into medical school, 2080 students were eligible to complete the survey and 1846 responded (89\%); 1982 were eligible at entry to wards (that is, during either their second or third year) and 1630 responded (82\%); 1901 were eligible at the final year and 1469 responded $(77 \%)$. Of the 2316 students who provided responses, $72 \%$ $(n=1658)$ did so at more than one time point; 971 responded at three time points, 687 at two, and 658 at one. Time specific school response rates ranged from $48 \%$ to $98 \%$, with $83 \%$ responding overall. Not all students were eligible and able to respond at all three survey points (for example, because of pursuing a complementary degree).

Questionnaires were usually administered after semimandatory activities (such as after exams, during orientation lunches, or at the end of a class) to encourage participation; students were informed that questionnaires were anonymous and confidential, and participation was voluntary. At some schools with lower response rates, we used Dillman's five stage mailing process ${ }^{15}$ to increase rates; surveys completed with this enhanced follow-up accounted for 5\% of the final year responses. School participation was encouraged by offering school specific data (in aggregate and without student identifiers) to school investigators. The median item nonresponse rate was $3 \%$, with lower rates for demographic information $(<1 \%), 2 \%$ missing on drinking variables, and between $5-10 \%$ on counselling variables. All available information was used in each analysis.

\section{Description of variables}

The three questions on alcohol have been used in a large national US survey and have been validated previously. ${ }^{16}$ The questions were:
- During the past month, on about how many days did you drink any alcoholic beverage?

- On the days when you drank, about how many drinks did you drink, on average? (a drink is one can or bottle of beer or wine cooler [chilled wine with juice or water], one glass of wine, one cocktail, or one shot of liquor)

- How often in the past month did you have five or more drinks on one occasion?

Based on responses to these questions, medical students were classified into one of three groups: excessive drinkers, non-excessive drinkers, or non-drinkers. Consumption was classified as "excessive" in the previous month if it met at least one of these criteria: reported at least one occasion on which they consumed five or more drinks (that is, reported one or more episodes of binge drinking), or men who drank more than two drinks a day on average or women who drank more than one drink a day on average, based on their responses to the frequency and average quantity questions. This criterion corresponds to the at risk average drinking levels specified by the US National Institute for Alcohol Abuse and Alcoholism. ${ }^{17}$ Drinkers who did not meet criteria for excessive drinkers were defined as non-excessive drinkers, and those who drank no alcohol in the past month were classified as non-drinkers. We calculated the prevalence of excessive drinking by dividing the number of excessive drinkers by the total number of students, and multiplying by 100 .

Smoking questions were drawn from the same source. ${ }^{16}$

- Have you smoked at least 100 cigarettes in your entire life?

- Do you NOW smoke cigarettes every day, some days, or not at all?

- How long has it been since you quit smoking cigarettes?

- During the past 30 days, on the days you smoked, how many cigarettes did you smoke per day?

We also asked how many days of the past 30 did they

- Smoke part or all of a cigar

- Use any chewing tobacco, dip, or snuff

- Smoke any tobacco in a pipe

- Smoke part or all of a cigarette.

Our primary professional outcomes were two variables concerning medical students' counselling of patients on alcohol: the perceived relevance of alcohol counselling in the student's intended practice ("How relevant do you think talking to patients about alcohol will be in your intended practice?") and validated ${ }^{18}$ frequency of alcohol counselling ("With a typical general medicine patient, how often do you actually talk to patients about alcohol?"). The possible response categories for relevance were "not at all," "somewhat," and "highly." For frequency of counselling the response categories were "never-rarely," "sometimes," and "usually-always." We asked about relevance of counselling at all time points, while frequency was 
measured only in the final year questionnaire, as these students are actually involved in clinical care.

We assessed drinking and counselling behaviours based on characteristics that are known to affect drinking and counselling behaviours, including demographics, personal health related habits, opinions on prevention, intended specialty, and school environment relating to personal health promotion. We also asked (in two separate questions) about apparent attitudes of their medical school and peers towards medical students' alcohol use.

\begin{tabular}{|c|c|c|c|c|c|c|}
\hline \multirow[b]{2}{*}{ Characteristic } & \multirow[b]{2}{*}{ No of students } & \multicolumn{3}{|c|}{ Alcohol consumption in past month } & \multirow[b]{2}{*}{$\mathrm{X}^{2} \mathrm{P}$ value $\dagger$} & \multirow[b]{2}{*}{$\begin{array}{l}\text { Adjusted odds ratio } \\
\qquad(95 \% \mathrm{Cl}) \ddagger\end{array}$} \\
\hline & & $\begin{array}{l}\text { None } \\
(\%)\end{array}$ & $\begin{array}{c}\text { Non-excessive } \\
\text { (\%) }\end{array}$ & $\begin{array}{l}\text { Excessive } \\
\text { (\%) }\end{array}$ & & \\
\hline Overall & $4847 \S$ & 22 & 44 & 34 & & \\
\hline \multicolumn{7}{|l|}{ Time point: } \\
\hline First year & 1818 & 22 & 44 & 33 & \multirow{3}{*}{0.5} & 1.0 \\
\hline $\begin{array}{l}\text { Introduction to wards (third } \\
\text { year) }\end{array}$ & 1601 & 23 & 43 & 34 & & $1.0(0.9$ to 1.1$)$ \\
\hline Final year & 1428 & 21 & 43 & 37 & & $1.2(0.97$ to 1.4$)$ \\
\hline \multicolumn{7}{|l|}{ Intended specialty: } \\
\hline Primary care & 1669 & 26 & 47 & 27 & \multirow{3}{*}{0.001} & 1.0 \\
\hline Not primary care & 2444 & 20 & 41 & 39 & & 1.4 (1.2 to 1.6$)$ \\
\hline Undecided & 690 & 22 & 43 & 36 & & 1.3 (0.98 to 1.8$)$ \\
\hline \multicolumn{7}{|l|}{ Sex: } \\
\hline Female & 2227 & 23 & 53 & 24 & \multirow{2}{*}{0.0001} & 1.0 \\
\hline Male & 2615 & 21 & 36 & 43 & & 2.4 (2.0 to 2.8$)$ \\
\hline \multicolumn{7}{|l|}{ Ethnicity: } \\
\hline Black/African American & 376 & 42 & 47 & 11 & \multirow{5}{*}{$<0.0001$} & 1.0 \\
\hline Asian & 906 & 32 & 43 & 25 & & 2.2 (1.2 to 4.2$)$ \\
\hline Hispanic & 204 & 15 & 52 & 32 & & $3.2(1.2$ to 8.4$)$ \\
\hline White & 3107 & 17 & 43 & 40 & & $4.5(2.4$ to 8.7$)$ \\
\hline Other & 239 & 26 & 40 & 34 & & $3.4(1.5$ to 7.6$)$ \\
\hline \multicolumn{7}{|l|}{ Marital status: } \\
\hline Married & 924 & 33 & 46 & 22 & \multirow{3}{*}{0.0001} & 1.0 \\
\hline Unmarried couple & 273 & 11 & 54 & 35 & & $2.5(1.6$ to 4.0$)$ \\
\hline Single/widowed/divorced & 3618 & 20 & 42 & 38 & & $2.5(2.0$ to 3.1$)$ \\
\hline \multicolumn{7}{|l|}{ Tobacco use in past month: } \\
\hline None, never smoked & 3538 & 28 & 48 & 24 & \multirow{4}{*}{$<0.0001$} & 1.0 \\
\hline Past smoker & 286 & 13 & 45 & 42 & & $2.4(1.6$ to 3.5$)$ \\
\hline Light/infrequent & 835 & 2 & 30 & 68 & & $6.2(4.9$ to 7.9$)$ \\
\hline $\begin{array}{l}110 \text { cigarettes/day or }>19 \text { days } \\
\text { with any tobacco }\end{array}$ & 175 & 4 & 21 & 75 & & $8.9(5.3$ to 14.8$)$ \\
\hline \multicolumn{7}{|l|}{ Strength of religious identity: } \\
\hline Very strong & 932 & 46 & 40 & 14 & \multirow{5}{*}{0.0001} & 1.0 \\
\hline Strong & 1202 & 24 & 45 & 31 & & $2.9(2.3$ to 3.7$)$ \\
\hline Moderate & 1293 & 15 & 44 & 41 & & $4.6(3.3$ to 6.5$)$ \\
\hline Low & 845 & 8 & 43 & 48 & & $6.1(4.2$ to 8.9$)$ \\
\hline None & 546 & 15 & 47 & 38 & & $4.0(2.5$ to 6.3$)$ \\
\hline \multicolumn{7}{|l|}{ Stress in past two weeks: } \\
\hline A lot & 1054 & 25 & 45 & 31 & \multirow{3}{*}{0.06} & 1.0 \\
\hline Moderate & 1927 & 21 & 46 & 32 & & $1.2(0.96$ to 1.4$)$ \\
\hline Little/none & 1831 & 21 & 40 & 39 & & 1.4 (1.02 to 1.9$)$ \\
\hline \multicolumn{7}{|l|}{ Stress in past 12 months: } \\
\hline A lot & 1568 & 23 & 45 & 33 & \multirow{3}{*}{0.004} & 1.0 \\
\hline Moderate & 2316 & 22 & 45 & 33 & & $1.2(1.1$ to 1.5$)$ \\
\hline Little/none & 922 & 20 & 38 & 41 & & 1.7 (1.2 to 2.3$)$ \\
\hline
\end{tabular}

*Consumption was classified as "excessive" in previous month if it met at least one of these criteria: reported at least one occasion on which $\geq 5$ drinks consumed (that is, reported one or more episodes of binge drinking), or $>2$ drinks/day on average in men or $>1$ drink/day on average in women, based on responses to frequency and average quantity questions. Those who drank less than excessively were classified as non-excessive drinkers. Those reporting no alcohol consumption in past month were classified as non-drinkers.

$+x^{2}$ test for association in contingency tables.

$\ddagger$ Odds ratio of excessive drinking ( $v$ non-excessive/non-drinkers) compared with reference group (listed with odds ratio=1.0), controlled for sex. §Sum of observations in various strata might not sum to total number of observations (4945) because of non-response. 
Table 2 |Alcohol consumption among US medical students (1999-2003) and its association with attitudinal and environmental characteristics

\begin{tabular}{|c|c|c|c|c|c|c|}
\hline \multirow[b]{2}{*}{ Characteristic } & \multirow[b]{2}{*}{ No of students } & \multicolumn{3}{|c|}{ Alcohol consumption in past month } & \multirow[b]{2}{*}{$X^{2} P$ value* } & \multirow[b]{2}{*}{$\begin{array}{l}\text { Adjusted odds } \\
\text { ratio }(95 \% \mathrm{Cl}) \dagger\end{array}$} \\
\hline & & $\begin{array}{c}\text { None } \\
\text { (\%) }\end{array}$ & $\begin{array}{c}\text { Non-excessive } \\
\text { (\%) }\end{array}$ & $\begin{array}{l}\text { Excessive } \\
\text { (\%) }\end{array}$ & & \\
\hline \multicolumn{7}{|c|}{ "I will be able to provide more credible and effective counselling if I drink alcohol in moderation or not at all": } \\
\hline Strongly agree & 313 & 27 & 48 & 25 & \multirow{4}{*}{0.0001} & 1.0 \\
\hline Agree & 744 & 21 & 45 & 34 & & $1.5(1.1$ to 2.1$)$ \\
\hline Neither agree/disagree & 218 & 17 & 38 & 45 & & $2.3(1.5$ to 3.3$)$ \\
\hline Disagree/strongly disagree & 83 & 8 & 27 & 65 & & $5.0(2.9$ to 8.7$)$ \\
\hline \multicolumn{7}{|l|}{ Peers' attitudes toward alcohol useł: } \\
\hline No obvious attitude & 314 & 26 & 43 & 31 & \multirow{4}{*}{0.03} & 1.0 \\
\hline We shouldn't drink & 57 & 46 & 25 & 30 & & $0.9(0.2$ to 3.6$)$ \\
\hline We should drink in moderation & 1225 & 23 & 46 & 31 & & 1.1 (0.7 to 1.7$)$ \\
\hline Drinking is a good release & 1316 & 19 & 41 & 39 & & $1.6(1.3$ to 2.0$)$ \\
\hline \multicolumn{7}{|l|}{ School's attitude toward alcoholł: } \\
\hline No obvious attitude & 832 & 20 & 47 & 34 & \multirow{4}{*}{0.006} & 1.0 \\
\hline We shouldn't drink & 356 & 55 & 29 & 15 & & $0.3(0.1$ to 0.8$)$ \\
\hline Drink in moderation & 1426 & 15 & 47 & 39 & & $1.3(1.03$ to 1.6$)$ \\
\hline Drinking is a good release & 305 & 24 & 35 & 42 & & 1.3 (0.96 to 1.7$)$ \\
\hline
\end{tabular}

${ }^{*} x^{2}$ test for association in contingency tables.

†Odds ratio of excessive drinking ( $v$ non-excessive/non-drinkers) compared with reference group (odds ratio=1.0), controlled for sex.

$\ddagger$ Questions asked only at introduction to wards and during final year.

\section{Statistical analysis}

We tested the bivariate associations between our three outcomes (drinking, counselling relevance, and counselling frequency) and independent variables with $\chi^{2}$ test. Because of the number of associations being tested, we limited our discussion of significant results to those

Table 3 | Drinking characteristics of US medical students (1999-2003) who consume alcohol, by sex and category of alcohol consumption*

\begin{tabular}{llclll} 
Drinking & \multicolumn{2}{c}{ Non-excessive $(\%)(n=2108)$} & & \multicolumn{2}{c}{ Excessive $(\%)(n=1666)$} \\
\cline { 2 - 3 } $\begin{array}{l}\text { characteristic } \\
\text { (past month) }\end{array}$ & $\begin{array}{c}\text { Men } \\
(n=937)\end{array}$ & $\begin{array}{c}\text { Women } \\
(n=1171)\end{array}$ & & $\begin{array}{c}\text { Men } \\
(n=1126)\end{array}$ & $\begin{array}{l}\text { Women } \\
(n=540)\end{array}$
\end{tabular}

Days of drinking:

\begin{tabular}{lcccc}
$1-4$ & 63 & 64 & 17 & 17 \\
\hline $5-9$ & 24 & 24 & 35 & 38 \\
\hline $10-14$ & 9 & 9 & 24 & 22 \\
\hline $15-19$ & 2 & 2 & 10 & 9 \\
\hline $20-24$ & 2 & 0 & 8 & 7 \\
\hline 25 & 1 & 0 & 5 & 6
\end{tabular}

Usual No of drinks per drinking day:

\begin{tabular}{lcccc}
\hline 1 & 50 & 55 & 9 & 11 \\
\hline 2 & 37 & 37 & 29 & 42 \\
\hline 3 & 11 & 8 & 28 & 25 \\
\hline 4 & 3 & 0 & 16 & 15 \\
\hline$\geq 5$ & N/A & N/A & 18 & 7 \\
\hline No of occasions with $\geq 5$ drinks: & & & \\
\hline 1 & N/A & N/A & 39 & 56 \\
\hline $2-3$ & N/A & N/A & 33 & 30 \\
\hline $4-5$ & N/A & N/A & 15 & 9 \\
\hline$\geq 6$ & N/A & N/A & 13 & 5 \\
\hline
\end{tabular}

$\mathrm{N} / \mathrm{A}=$ not applicable.

${ }^{*}$ Consumption classified as "excessive" in previous month if it met at least one of: reported at least one occasion on which $\geq 5$ drinks consumed (that is, reported one or more episodes of binge drinking), or drank $>2$ drinks/day on average in men or $>1$ drink/day on average in women, based on responses to frequency and average quantity questions. Those who drank less than excessively were classified as non-excessive drinkers. Those reporting no alcohol consumption in past month were classified as non-drinkers. with $\mathrm{P}<0.01$. We calculated sex adjusted odds ratios for excessive drinking and crude odds ratios for relevance and frequency of alcohol counselling, with their $95 \%$ confidence intervals, with generalised estimating equations with robust variance estimation.

We used logistic regression analysis to assess the relation between the perceived relevance and frequency of counselling with three independent variables: the amount of training in alcohol counselling ("extensive" versus less than extensive); the degree of agreement with the statement, "Physicians have a responsibility to promote prevention with their patients"; and alcohol consumption in the past month. We adjusted for potential confounders, including sex and current intended specialty. For the analysis, perceived relevance of alcohol related counselling was dichotomised as highly relevant versus any lesser response and the frequency of counselling as usuallyalways counselling versus less often or no counselling. All measurements were reported on the senior year questionnaire. We used SUDAAN software,${ }^{19}$ which is designed for the analysis of clustered data, for all data analysis, treating each school as a cluster and each student's multiple responses as subclusters in the analyses. Model parameters were estimated with a SUDAAN procedure by using working exchangeable generalised estimating equations with robust variance estimation. Model fit was also assessed via standardised deviance residuals and the Hosmer-Lemeshow goodness of fit test. ${ }^{20}$

\section{RESULTS}

Most (78\%, 3777/4847) students reported drinking alcohol in the past month, and 34\% (1668/4847) drank excessively (540/2227 (24\%) women and 1126/2615 (43\%) men); these proportions changed little over time 
at medical school (table 1). Of those who met the criteria for excessive drinkers, nearly all (99\%, 1661/ 1668) reported binge drinking at least once in the past month, and 36\% (594/1668) reported three or more binge episodes (data not shown). In the subset who responded at all time points, $86 \%(267 / 310)$ of those reporting excessive drinking at year one made the same report on at least one subsequent questionnaire; 59\% $(184 / 310)$ reported heavy drinking at all points. Four fifths of first year non-drinkers (167/208) reported no drinking on at least one other questionnaire, and only 13 later reported excessive drinking.

Although similar proportions of students who were intending to practise in primary and non-primary care drank alcohol, non-primary care students were more likely to drink excessively; this was true even after we adjusted for sex disparity in specialty choice (table 1). And although almost equal proportions of men and women drank alcohol, men were more than twice as likely to drink excessively. By race, black or AfricanAmerican students were least likely to drink alcohol and drink excessively, while white students were most likely to do so. When stratified by relationship status, married students were least likely to drink or to drink excessively.

Table $4 \mid$ Alcohol counselling by US medical students (1999-2003): self reports on relevance to intended practice, training, confidence, and frequency. Figures are numbers (percentages) of students

Counselling question First year Orientation to wards Final year $\mathrm{X}^{2} \mathrm{P}$ (for time)

How relevant do you think talking to patients about alcohol will be in your intended practice?

Total (all specialties):

\begin{tabular}{|c|c|c|c|c|}
\hline Not at all & $106(6)$ & $56(4)$ & $150(12)$ & \multirow{3}{*}{$<0.002$} \\
\hline Somewhat & $734(40)$ & $531(35)$ & $563(42)$ & \\
\hline Highly & $970(54)$ & $919(61)$ & $606(46)$ & \\
\hline \multicolumn{5}{|l|}{ Primary care: } \\
\hline Not at all & $36(5)$ & 4 (1) & $5(1)$ & \multirow{3}{*}{$<0.0001^{*}$} \\
\hline Somewhat & 279 (35) & $98(23)$ & $160(39)$ & \\
\hline Highly & $476(60)$ & $330(76)$ & 241 (59) & \\
\hline \multicolumn{5}{|c|}{ Non-primary care: } \\
\hline Not at all & $56(9)$ & $45(6)$ & $154(17)$ & \multirow{3}{*}{$0.003^{*}$} \\
\hline Somewhat & $288(44)$ & $325(42)$ & $388(44)$ & \\
\hline Highly & $315(48)$ & $397(52)$ & 344 (39) & \\
\hline
\end{tabular}

How confident are you about talking to patients about alcohol?†

\begin{tabular}{|c|c|c|c|c|}
\hline Not at all & - & $63(4)$ & $20(1)$ & \multirow{3}{*}{0.001} \\
\hline Somewhat & - & 806 (53) & $657(48)$ & \\
\hline Highly & - & $638(42)$ & $686(50)$ & \\
\hline \multicolumn{5}{|c|}{ How much training have you had on talking to patients about alcohol? $†$} \\
\hline None & - & $129(9)$ & $26(2)$ & \multirow{3}{*}{0.0003} \\
\hline Some & - & $1087(72)$ & $837(63)$ & \\
\hline Extensive & - & 294 (19) & $458(35)$ & \\
\hline
\end{tabular}

With a typical general medicine patient, how often do you actually perform this activity? $\ddagger$

Never/rarely

-

Sometimes

$-$

-

$110(8)$

Usually/always

$-$

$892(64)$

*In addition to significant $x^{2}$, proportion responding "highly" ( $v$ "less than highly") followed significant quadratic trend over time.

tQueried during orientation to wards and during final year.

‡Queried only during final year.
Several personal habits and beliefs were associated with drinking habits (table 1). Nearly all current smokers reported drinking alcohol, and they were nearly three times more likely to drink excessively than those who had never smoked (69\% (699/1010) v 24\% (841/3538)). Strong religious identity was associated with more abstention and less excessive use of alcohol. Rates of excessive drinking were highest among those reporting lower stress levels.

Those who did not drink excessively agreed more strongly that one would provide better counselling if one abstained or did not drink excessively. Academic and peer environment were also associated with drinking behaviours (table 2); there was a modest relation between students' perception of school attitude regarding alcohol and the report of excessive drinking. The odds of excessive drinking were $60 \%$ higher if peers' attitude was that "drinking is a good release" compared with "no obvious attitude." There was a strong relation between a school's support for non-drinking and students' drinking behaviours; however, this relation was strongly influenced by findings from one religiously affiliated school that discouraged alcohol use. There were no significant relations (data not shown, $\mathrm{P}>0.7$ ) between attitudes of school or peers versus perceived relevance or frequency of alcohol counselling.

Among excessive drinkers, about three quarters of men and women drank on 14 or fewer days in the past month (table 3). On the days excessive drinkers consumed alcohol, 62\% (696/1124) of men drank three or more drinks and $89 \%$ (478/539) of women drank two or more drinks. Furthermore, 18\% (201/1124) of male and $22 \%(117 / 539)$ of female excessive drinkers reported that their usual alcohol consumption on days they drank met or exceeded binge levels (that is, five or more drinks for men, four or more drinks for women). Among excessive drinkers, 61\% (691/1126) of men and $44 \%$ (229/520) of women reported binge drinking on multiple occasions in the past 30 days.

When asked how relevant speaking to patients about alcohol would be in their intended medical practice, students intending a primary care specialty were significantly more likely to answer "highly relevant"; this was the case for all time points in school $(\mathrm{P}<0.01$, table 4). During their years of clinical training, students' perception that alcohol counselling was highly relevant declined from $76 \%(330 / 432)$ to $59 \%$ (241/406) among those intending to pursue primary care specialties, and from $52 \%(397 / 767)$ to $39 \%$ (344/ 886) among those intending non-primary care specialties. The proportion of students reporting high confidence in alcohol counselling increased from $42 \%(638 / 1507)$ at orientation to wards to $50 \%$ (686/ 1363) during the final year. Only a minority at either entrance to wards $(19 \% ; 294 / 1510)$ or the final year $(35 \% ; 458 / 1321)$ thought they had extensive training in alcohol counselling, although nearly all said they had at least some training by senior year. Overall, 28\% (391/ 1393) of seniors reported usually or always talking to 
Table 5 |Relation of personal characteristics with perceived relevance to intended practice and self reported frequency of counselling general medicine patients, reported during senior year of US medical school (2003)

\begin{tabular}{|c|c|c|c|c|c|c|}
\hline & \multicolumn{3}{|c|}{ Highly relevant to practice } & \multicolumn{3}{|c|}{ Usually/always counsel } \\
\hline & $\begin{array}{c}\text { No of } \\
\text { students* }\end{array}$ & $\begin{array}{c}\% \text { of } \\
\text { students }\end{array}$ & $\begin{array}{r}\text { Crude OR } \\
(95 \% \mathrm{Cl})\end{array}$ & $\begin{array}{c}\text { No of } \\
\text { students* }\end{array}$ & $\begin{array}{c}\% \text { of } \\
\text { students }\end{array}$ & $\begin{array}{l}\text { Crude OR } \\
(95 \% \mathrm{Cl})\end{array}$ \\
\hline Total & 1330 & $46(41$ to 51$)$ & & 1394 & $28(24$ to 31$)$ & \\
\hline \multicolumn{7}{|l|}{ Sex: } \\
\hline Men & 704 & 39 & 1.0 (ref) & 739 & 26 & 1.0 (ref) \\
\hline Women & 625 & 53 & 1.8 (1.4 to 2.2$)$ & 653 & 31 & $1.3(0.97$ to 1.6$)$ \\
\hline \multicolumn{7}{|l|}{ Ethnicity: } \\
\hline White & 847 & 42 & 1.0 (ref) & 887 & 25 & 1.0 (ref) \\
\hline Asian & 253 & 49 & $1.4(1.0$ to 1.8$)$ & 257 & 34 & $1.6(1.1$ to 2.2$)$ \\
\hline $\begin{array}{l}\text { Black/African } \\
\text { American }\end{array}$ & 109 & 62 & $2.3(1.4$ to 3.9$)$ & 116 & 39 & $1.9(1.1$ to 3.5$)$ \\
\hline Hispanic & 55 & 47 & $1.2(0.6$ to 2.5$)$ & 57 & 30 & 1.3 (0.9 to 1.8$)$ \\
\hline Other & 64 & 47 & $1.2(0.8$ to 1.9$)$ & 73 & 30 & $1.3(0.9$ to 1.9$)$ \\
\hline \multicolumn{7}{|c|}{ Alcohol drinking in past month†: } \\
\hline None & 278 & 55 & 1.7 (1.1 to 2.7$)$ & 291 & 32 & 1.4 (1.03 to 2.0$)$ \\
\hline Non-excessive & 567 & 45 & $1.2(0.9$ to 1.5$)$ & 589 & 30 & 1.3 (0.96 to 1.8$)$ \\
\hline Excessive & 465 & 42 & 1.0 (ref) & 494 & 24 & 1.0 (ref) \\
\hline
\end{tabular}

*Denominator for percentage displayed. Numbers for various characteristics might not add up to row total because of item non-response for those characteristics.

†Consumption classified as "excessive" in previous month if it met at least one of: reported at least one occasion on which $\geq 5$ drinks consumed (that is, reported one or more episodes of binge drinking), or if men drank $>2$ drinks/day on average or if women drank $>1$ drink/day on average, based on responses to frequency and average quantity questions. Those who drank less than excessively were classified as non-excessive drinkers. Those reporting no alcohol consumption in past month were classified as non-drinkers.

their general medical patients about their alcohol consumption.

Nearly half $(46 \% ; 606 / 1330)$ of final year students considered alcohol counselling highly relevant to their intended specialty (tables 5 and 6). Characteristics associated with reporting higher perceived relevance of alcohol counselling included: being female; being of black/African American race; abstaining from alcohol in the past month; intending to go into primary care; having extensive training in the topic; feeling highly confident in alcohol counselling; strongly agreeing that moderation in their personal drinking habits was associated with credible and effective alcohol counselling; strongly agreeing that counselling on healthy lifestyles is effective; expressing more interest in prevention than treatment; and agreeing that physicians have a responsibility to promote prevention.

Characteristics associated with frequent alcohol counselling among senior medical students included: being Asian or black/African American; abstaining from alcohol or drinking non-excessively; having extensive training in the topic; feeling highly confident in alcohol counselling; strongly agreeing that moderation in their personal drinking habits is associated with credible and effective alcohol counselling; strongly agreeing that counselling on healthy lifestyles is effective; and strongly agreeing that physicians have a responsibility to promote prevention. Sex, intended specialty, and interest in prevention compared with treatment were not significantly associated with frequency of counselling. Among those who disagreed that moderation in their personal drinking habits was associated with credible and effective alcohol counselling, 19\% (15/81) rarely or never counselled, compared with $7 \%(92 / 1277)$ of others (data not shown).

In multivariate models, extensive training in alcohol counselling was associated with over twice the odds of a final year student's belief that alcohol counselling would be relevant to their practice (adjusted odds ratio $2.3,95 \%$ confidence interval 1.6 to 3.3 ) and reporting that they often counselled patients about their alcohol consumption (2.2, 1.5 to 3.3) (table 7). Personal alcohol consumption (that is, being either a non-drinker or non-excessive drinker) and belief in one's responsibility to promote prevention were somewhat (but nonsignificantly) associated with talking with patients about alcohol consumption. Intention to go into a primary care specialty and being female were associated with higher odds of reporting high relevance of alcohol counselling but were not significantly associated with higher odds of talking to patients about alcohol.

\section{DISCUSSION}

\section{Summary}

In this study of alcohol consumption among US medical students about a third $(24 \%$ of women and $43 \%$ of men) reported excessive drinking in the previous month, typically in the form of binge drinking, and usually (among excessive drinkers) on multiple occasions, with frequencies changing little over time at medical school. Only a quarter of final year students routinely assessed their patients' drinking behaviours, and students' perceptions of the relevance and frequency of performing alcohol counselling were significantly associated with their training in alcohol 
counselling; only half of final year students reported that they were highly confident about their ability to discuss alcohol with their patients.

Comparison of medical students' alcohol consumption with other populations and previous literature

Our findings are consistent with earlier studies of drinking among US medical students. ${ }^{21-24}$ For example, a study in the mid-1980s of 341 first year medical students at four schools found that $44 \%$ were either "frequent" or "heavy" drinkers; these categories involved either occasional or frequent consumption that included binge drinking. ${ }^{25}$ This bingeing prevalence was about 50\% higher than that reported in a survey of 548 medical students from eight US medical schools in the mid-1990s. ${ }^{26}$ Studies in the United Kingdom, ${ }^{27}$ Germany, ${ }^{28}$ and New Zealand ${ }^{29}$ showed rates of bingeing in medical students similar to or higher than rates in the US.

Our reported rates of binge drinking were lower than the $51 \%$ of $18-24$ year olds, and $40 \%$ of $25-34$ year old
Americans in 2002 who reported consuming five or more drinks at least once in the past month ${ }^{7}$ and lower than the rates in 1999 US college seniors (45\% in the past two weeks, both for highly competitive colleges and for all final year students). ${ }^{30}$ They were, however, substantially higher than bingeing rates reported by female doctors aged $30-70(0.1 \% \text { in the past month })^{10}$ and did not decline during medical school.

Overall, $79 \%$ of male and $77 \%$ of female medical students reported consuming alcohol in the past 30 days. Consistent with other data showing lower rates of abstention with higher socioeconomic status, these rates of use were slightly higher than national rates: in the US 77\% of men and $65 \%$ of women aged 25-44 consumed alcohol in 2001. ${ }^{31}$ The only previous national data collected on alcohol use among medical students (conducted among 2046 final year students in 1987) found that $87 \%$ of women and $88 \%$ of men reported alcohol use in the previous month, with no assessments of frequency or quantity. ${ }^{21}$ Similar numbers $(83 \%$ of women and $88 \%$ of men) were reported in

Table $6 \mid$ Relation of professional characteristics with perceived relevance $(n=1330)$ to intended practice and self reported frequency of counselling general medicine patients ( $n=1394)$ reported during final year of US medical school (2003)

\begin{tabular}{|c|c|c|c|c|c|c|}
\hline & \multicolumn{3}{|c|}{ Highly relevant to practice } & \multicolumn{3}{|c|}{ Usually/always counsel } \\
\hline & $\begin{array}{c}\text { No of } \\
\text { students* }\end{array}$ & $\begin{array}{l}\text { \% of } \\
\text { students }\end{array}$ & $\begin{array}{l}\text { Crude OR } \\
(95 \% \mathrm{Cl})\end{array}$ & $\begin{array}{c}\text { No of } \\
\text { students* }\end{array}$ & $\begin{array}{l}\text { \% of } \\
\text { students }\end{array}$ & $\begin{array}{l}\text { Crude OR } \\
(95 \% \mathrm{Cl})\end{array}$ \\
\hline \multicolumn{7}{|l|}{ Intended specialty: } \\
\hline Primary care & 406 & 59 & 2.3 (1.8 to 3.0$)$ & 421 & 29 & $1.1(0.8$ to 1.4$)$ \\
\hline Non-primary care & 887 & 39 & 1.0 (ref) & 935 & 27 & 1.0 (ref) \\
\hline \multicolumn{7}{|l|}{ Training in alcohol counselling: } \\
\hline Extensive & 451 & 59 & 2.3 (1.7 to 3.2$)$ & 455 & 40 & 2.3 (1.6 to 3.3 ) \\
\hline Less than extensive & 835 & 39 & 1.0 (ref) & 857 & 22 & 1.0 (ref) \\
\hline \multicolumn{7}{|c|}{ Confidence in alcohol counselling: } \\
\hline Highly confident & 663 & 55 & $2.2(1.6$ to 3.0$)$ & 680 & 36 & 2.5 (1.7 to 3.6$)$ \\
\hline Less than highly & 631 & 36 & 1.0 (ref) & 672 & 19 & 1.0 (ref) \\
\hline \multicolumn{7}{|c|}{ I will be able to provide more credible and effective counselling if I drink alcohol in moderation or not at all: } \\
\hline Strongly agree & 306 & 57 & 1.0 (ref) & 317 & 37 & 1.0 (ref) \\
\hline Agree & 721 & 44 & $0.6(0.4$ to 0.8$)$ & 747 & 26 & $0.6(0.5$ to 0.8$)$ \\
\hline Neither & 197 & 33 & $0.4(0.2$ to 0.6$)$ & 214 & 21 & $0.4(0.3$ to 0.7$)$ \\
\hline Disagree/strongly disagree & 79 & 48 & $0.7(0.5$ to 1.1$)$ & 81 & 301 & $0.7(0.4$ to 1.4$)$ \\
\hline \multicolumn{7}{|c|}{ Patients are more likely to adopt healthier lifestyles if physicians counsel them to do so: } \\
\hline Strongly agree & 232 & 55 & 1.0 (ref) & 239 & 38 & 1.0 (ref) \\
\hline Agree & 810 & 44 & $0.7(0.5$ to 0.9$)$ & 844 & 25 & $0.6(0.4$ to 0.8$)$ \\
\hline Neither & 176 & 39 & $0.5(0.3$ to 0.9$)$ & 190 & 28 & $0.7(0.3$ to 1.3$)$ \\
\hline Disagree/ strongly disagree & 79 & 48 & $0.8(0.4$ to 1.4$)$ & 80 & 28 & $0.6(0.3$ to 1.3$)$ \\
\hline \multicolumn{7}{|c|}{ I am less interested in prevention than treatment: } \\
\hline Strongly agree & 77 & 32 & 1.0 (ref) & 82 & 28 & 1.0 (ref) \\
\hline Agree & 293 & 39 & 1.3 (0.8 to 2.2$)$ & 308 & 26 & 0.9 (0.6 to 1.4$)$ \\
\hline Neither & 285 & 39 & $1.3(0.8$ to 2.2$)$ & 302 & 25 & $0.9(0.5$ to 1.5$)$ \\
\hline Disagree & 488 & 48 & $2.0(1.02$ to 3.7$)$ & 503 & 27 & $0.9(0.5$ to 1.7$)$ \\
\hline Strongly disagree & 156 & 70 & $4.8(2.2$ to 10.5$)$ & 159 & 41 & $1.8(0.95$ to 3.3$)$ \\
\hline \multicolumn{7}{|c|}{ Physicians have a responsibility to promote prevention with their patients: } \\
\hline Strongly agree & 340 & 56 & $2.3(1.5$ to 3.5$)$ & 352 & 36 & $2.6(1.3$ to 5.1$)$ \\
\hline Agree & 831 & 43 & $1.4(1.05$ to 1.8$)$ & 858 & 26 & $1.6(0.8$ to 3.0$)$ \\
\hline $\begin{array}{l}\text { Neither disagree/ strongly } \\
\text { disagree }\end{array}$ & 124 & 35 & 1.0 (ref) & 142 & 18 & 1.0 (ref) \\
\hline
\end{tabular}

*Denominator for percent displayed. Numbers for various characteristics might not sum to $\mathrm{n}$ for relevance or frequency because of item non-response for those characteristics. 
Table 7| Multivariate testing of association of training, drinking, and prevention attitudes with perceived relevance and self reported frequency of alcohol counselling among US medical school seniors (2002-3). Odds ratios are adjusted* and presented with $95 \%$ confidence intervals and $P$ values $\dagger$

Relevance to intended specialty Frequency of counselling $(n=1215)$ $(n=1237)$

Modifiable characteristics

Training in alcohol counselling:

\begin{tabular}{lcc}
\hline None/some & 1.0 & 1.0 \\
\hline Extensive & $2.3(1.6$ to 3.3$)$ & $2.2(1.5$ to 3.3$)$ \\
\hline P value & 0.0002 & 0.0006 \\
\hline
\end{tabular}

Alcohol drinking in past month:

\begin{tabular}{lcc}
\hline Excessive & 1.0 & 1.0 \\
\hline Non-excessive & $1.0(0.7$ to 1.3$)$ & $1.2(0.8$ to 1.9$)$ \\
\hline None & $1.4(0.9$ to 2.3$)$ & $1.4(0.9$ to 2.1$)$ \\
\hline Pvalue & 0.1 & 0.3
\end{tabular}

Physicians have a responsibility to promote prevention with their patients:

\begin{tabular}{lcc}
\hline Strongly agree & $1.4(0.8$ to 2.4$)$ & $1.9(0.8$ to 4.4$)$ \\
\hline Agree & $1.1(0.7$ to 1.6$)$ & $1.3(0.6$ to 2.7$)$ \\
\hline $\begin{array}{l}\text { Neutral/disagree/strongly } \\
\text { disagree }\end{array}$ & 1.0 & 1.0 \\
\hline P value & 0.09 & 0.08 \\
\hline
\end{tabular}

\section{Control variables}

Sex:

\begin{tabular}{|c|c|c|}
\hline Female & 1.5 (1.2 to 1.9$)$ & $1.1(0.8$ to 1.4$)$ \\
\hline Male & & 1.0 \\
\hline$P$ value & 0.002 & 0.6 \\
\hline \multicolumn{3}{|c|}{ Current intended specialty: } \\
\hline Primary care & 2.2 (1.8 to 2.8$)$ & $1.0(0.7$ to 1.3$)$ \\
\hline Non-primary care & 1.0 & 1.0 \\
\hline$P$ value & $<0.0001$ & 0.9 \\
\hline
\end{tabular}

*Odds of reporting "highly relevant" or "usually/always" compared with reference group, adjusted for all other variables listed.

†Satterthwaite adjusted F test for significance of covariate adjusted relation of characteristic with outcome.

1987 for residents' alcohol use in the past month, also without assessments of frequency or quantity. ${ }^{32}$

While bingeing rates in medical students were lower than their peers', bingeing is still a prevalent behaviour. This suggests that, as with their poor dietary habits (but in contrast to their relatively good smoking and physical activity habits), ${ }^{33}$ alcohol use has not yet been sufficiently addressed as an important health risk behaviour among US medical students.

\section{Correlates of medical students' alcohol counselling} practices

The relatively low rate of US medical students who provide alcohol counselling is also of concern. Screening and counselling for alcohol misuse in adults in primary care, including non-dependent excessive drinking (such as binge drinking), are strongly recommended by the US Preventive Services Task Force ${ }^{3}$ and are consistent with the conclusions of the Institute of Medicine about the importance of "broadening the base" of alcohol counselling to include all patterns of alcohol consumption that increase the risk of health problems. ${ }^{34}$ Furthermore, screening and brief counselling interventions are particularly high impact and cost effective clinical preventive services, ${ }^{4}$ and a high proportion of conditions leading to medical visits and inpatient admissions are alcohol related or are exacerbated by excessive drinking. ${ }^{356}$ Despite the efficiency of counselling, our finding that less than a third of students routinely counsel general medical patients about their alcohol consumption is consistent with studies that show only a small proportion of patients are screened by physicians about their alcohol use. ${ }^{537}$ Our findings are also consistent with other studies pointing to a lack of adequate or appropriate training in alcohol counselling as an important contributor to low rates of screening. ${ }^{838-40}$ More encouragingly, like some other behaviours studied in this population and elsewhere, ${ }^{41}$ we found that more training was an important predictor of subsequent preventive counselling behaviour among senior medical students.

In bivariate analysis, excessive drinking was associated with lower perceived relevance and frequency of alcohol counselling; findings were similar but not significant in multivariate analysis. A relation between personal and clinical practices has been found among US physicians for many behaviours, including drinking alcohol and counselling patients about alcohol: only $32 \%$ of female physicians who reported drinking more than two drinks a week (the 75th centile for alcohol intake) typically counselled patients about alcohol at least once a year compared with $42 \%$ of those who drank two or fewer drinks a week $(\mathrm{P}<0.001$ for the difference between the two groups' counselling rates). ${ }^{10}$ Similarly, bivariate analyses showed that students whose peers who did not encourage drinking as a release, and those attending a school that encouraged abstention, were somewhat less likely to drink excessively; this behaviour could be considered part of a professionalism curriculum. ${ }^{42}$

\section{Strengths and weaknesses}

Our study's strengths include a high response rate, a large and representative sample, the longitudinal design, and linked data over time. Our findings, however, are also subject to some limitations. Although

\section{WHAT IS ALREADY KNOWN ON THIS TOPIC}

Screening and brief counselling help to reduce excessive alcohol consumption and related harms

Drinking behaviours among medical students have important implications for the health of the general population

\section{WHAT THIS STUDY ADDS}

The prevalence of binge drinking among US medical students is somewhat lower than their peers in the general population, though still quite high and substantially higher than rates reported by US female physicians

Few medical students usually discussed alcohol with patients, but as personal and educational characteristics are associated with their perceived relevance and frequency of counselling, interventions on these characteristics could improve students' rates of alcohol counselling 
not all students responded during all three time periods, response rates for each time period exceeded $75 \%$. Data are limited by being survey data (rather than qualitative or interview) from schools with variations within and between them and from self report. Our question on frequency of alcohol counselling, however, was validated with extensive standardised testing, ${ }^{18}$ with a strong relation shown between medical students' self reported alcohol counselling and their actual counselling, as reported by standardised patients. While we have validated some of our data on personal health practice, ${ }^{43}$ rates of binge drinking are difficult to validate and are likely to be underestimated because of bias due to social desirability, particularly among health professionals. In addition, we did not use a sex specific definition of binge drinking and might have underestimated the prevalence of binge drinking among women.

Medical students' personal and clinical attitudes about alcohol have important implications for their current care of patients. Furthermore, drinking practices in young adulthood help to establish patterns for later drinking. ${ }^{44}$ As medical school environments might influence students' consumption (through both the formal and informal or hidden curriculum), ${ }^{45}$ it might be useful to consider whether efforts should be made to alter the drinking environments at US medical schools to discourage excessive drinking (though this might be difficult to accomplish). ${ }^{4647}$ If medical students are better educated about guidelines for low risk drinking and screening and counselling for alcohol misuse, they might be more likely to adhere to clinical prevention guidelines and be better equipped to identify and reduce excessive drinking among their patients. Medical schools should also consider supporting the implementation of effective interventions to reduce excessive drinking among medical students and the general population. ${ }^{48-50}$

Contributors: EF was responsible for the conception, design, and interpretation of data, for drafting the article and revising it, and providing final approval of the version to be published. She is guarantor. LE contributed to study design, was responsible for data analysis and interpretation, contributed to article revision for important intellectual content, and approved the final version. TN contributed to study design, analysis and interpretation of data, drafting components of the article critical revisions, and approved the final version. RB contributed to study design, analysis and interpretation of data, drafting components of the article, critical revisions, and approved the final version. Funding: This work was supported by the American Cancer Society, Annenberg Physician Training Program, Canada Research Chair Program, and the Michael Smith Foundation for Health Research.

Competing interests: None declared.

Ethical approval: This work was approved by the institutional review board at Emory University, and informed consent was given by all participants. Provenance and peer review: Not commissioned; externally peer reviewed.

1 Centers for Disease Control. Alcohol-related disease impact (ARDI) software. Atlanta, GA: CDC, 2004.

2 Mokdad AH, Stroup D, Marks JS, Gerberding J. Actual causes of death in the United States, 2000. JAMA 2004;291:1238-45.

3 US Preventive Services Task Force. Screening and behavioral counseling interventions in primary care to reduce alcohol misuse. Rockville, MD: Agency for Healthcare Research and Quality, 2004.
4 Solberg LI, Maciosek MV, Edwards NM. Primary care intervention to reduce alcohol misuse: ranking its health impact and costeffectiveness. Am / Prev Med 2008;34:143-52.

5 Denny $\mathrm{CH}$, Serdula MK, Holtzman D, Nelson DE. Physician advice about smoking and drinking: are US adults being informed? Am J Prev Med 2003;24:71-4.

6 Coffield AB, Maciosek MV, McGinnis JM, Harris JR, Caldwell MB, Teutsch SM, et al. Priorities among recommended clinical preventive services. Am J Prev Med 2001;21:1-9.

7 Town M, Naimi TS, Mokdad AH, Brewer RD. Health care access among U.S. adults who consume alcohol excessively: missed opportunities for prevention. Prev Chronic Dis 2006;3:A53.

8 Frost-Pineda K, VanSusteren T, Gold MS. Are physicians and medical students prepared to educate patients about alcohol consumption? J Addict Dis 2004;23:1-13.

9 Frank E. Physician health and patient care. JAMA 2004;291:637.

10 Frank E, Brogan D, Mokdad AH, Simoes E, Kahn HS, Greenberg RS. Health-related behaviors of women physicians vs other women in the United States. Arch Intern Med 1998;158:342-8.

11 American Association of Medical Colleges. Matriculant age at anticipated matriculation, 1992-2001: AAMC Data warehouse: Applicant matriculant file, 1999-2001. www.aamc.org/data/facts/ archive/famg112001a.htm

12 American Association of Medical Colleges. AAMC Data Warehouse: Student Records System as of December 12, 2000, reflecting those actively enrolled on October 31, 2000, 2001. www.aamc.org/data/ facts/archive/famg82001.htm

13 American Association of Medical Colleges. FACTS-Applicants, matriculants, and graduates-new entrants by gender and race/ ethnicity, 2000. www.aamc.org/data/facts/archive/famg42001a. htm

14 National Institutes of Health. Support to US medical schools, fiscal year 2000-2001. Bethesda, MD: NIH, 2005.

15 Dillman DA. Mail and internet surveys. The tailored design method. 2nd ed. New York: John Wiley, 2000.

16 Nelson DE. Reliability and validity of measures from the behavioral risk factor surveillance system (BRFSS). Soc Prev Med 2001;46(suppl 1):S3-42.

17 National Institute on Alcohol Abuse and Alcoholism. NIAAA Council approves binge drinking definition. NIAAA Newsletter 2004;3:3.

18 Frank E, McLendon L, Elon LK, Denniston M, Fitzmaurice D, Hertzberg V. Medical students' self-reported typical counseling practices are similar to those assessed using standardized patients. Med Gen Med 2005;7:2.

19 Shah BV. SUDAAN [program]. Research Triangle Park, NC: Research Triangle Institute, 2006.

20 Hosmer DW, Lemeshow S. Applied logistic regression. New York: John Wiley, 1989.

21 Baldwin DC, Hughes PH, Conard SE, Storr CL, Sheehan DV. Substance use among senior medical students. A survey of 23 medical schools. JAMA 1991;265:2074-8.

22 Delnevo CD, Abatemarco DJ, Gotsch AR. Health behaviors and health promotion/disease prevention perceptions of medical students. Am J Prev Med 1996;12:38-43.

23 Varga M, Buris L. Drinking habits of medical students call for better integration of teaching about alcohol into the medical curriculum. Alcohol Alcohol 1994;29:591-6.

24 Westermeyer J. Substance abuse among medical trainees: current problems and evolving resources. Am I Drug Alcohol Abuse 1988;14:393-404.

25 Forney MA, Ripley WK, Forney PD. A profile and prediction study of problem drinking among first-year medical students. Int J Addict 1988;23:767-79.

26 Mangus RS, Hawkins CE, Miller MJ. Tobacco and alcohol use among 1996 medical student graduates. JAMA 1998;280:1192-3.

27 Gill JS. Reported levels of alcohol consumption and binge drinking within the UK undergraduate student population over the last 25 years. Alcohol Alcohol 2002;37:109-20.

28 Keller S, Maddock JE, Laforge RG, Velicer WF, Basler HD. Binge drinking and health behavior in medical students. Addict Behav 2007;32:505-15.

29 Cape G, Hannah A, Sellman D. A longitudinal evaluation of medical student knowledge, skills and attitudes to alcohol and drugs. Addiction 2006;101:841-9.

30 Wechsler H, Lee JE, Kuo M, Lee H. College binge drinking in the 1990s: a continuing problem. J Am Coll Health 2000;48:199-210.

31 Fried VM, Prager K, MacKay AP, Xia H. Chartbook on trends in the health of Americans. Hyattsville, MD: National Center for Health Statistics, 2003.

32 Hughes PH, Conard SE, Baldwin DC, Storr CL, Sheehan DV. Resident physician substance use in the United States. JAMA 1991;265:2069-73.

33 Frank E, Carrera J, Elon LK, Hertzberg VS. Basic demographics, health practices, and health status of US medical students. Am J Prev Med 2006;31:499-505 
34 Institutes of Medicine. Broadening the base of treatment for alcohol problems. Washington, DC: Institutes of Medicine, 1990.

35 Committee on Treatment of Alcohol Problems, Centers for Disease Control and Prevention. Alcohol and public health. Atlanta, GA: National Academies Press, 1990.

36 Chen $\mathrm{CM}$, Yi H. Trends in alcohol-related morbidity among short-stay community hospital discharges, United States, 1979-2005.

Bethesda, MD: National Institutes of Health, National Institute on Alcohol Abuse and Alcoholism, 2007.

37 D’Amico EJ, Paddock SM, Burnam A, Kung FY. Identification of and guidance for problem drinking by general medical providers: results from a national survey. Med Care 2005;43:229-36.

38 Friedmann PD, McCullough D, Chin MH, Saitz R. Screening and intervention for alcohol problems. A national survey of primary care physicians and psychiatrists. J Gen Intern Med 2000;15:84-91.

39 Hoffman NG, Chang AJ, Lewis DC. Medical student attitudes towards drug addiction policy. J Addict Dis 2000;19:1-12.

40 Isaacson JH, Fleming M, Kraus M, Kahn R, Mundt M. A national survey of training in substance use disorders in residency programs. J Stud Alcohol 2000;61:912-5.

41 Roche AM, Eccleston P, Sanson-Fisher R. Teaching smoking cessation skills to senior medical students: a block-randomized controlled trial of four different approaches. Prev Med 1996;25:251-8.

42 Cruess SR, Cruess RL. Understanding medical professionalism: a plea for an inclusive and integrated approach. Med Educ 2008;42:755-7.
43 Spencer EH, Elon LK, Hertzberg VS, Stein AD, Frank E. Validation of a brief diet survey instrument among medical students. J Am Diet Assoc 2005;105:802-6.

44 McCarty CA, Ebel BE, Garrison MM, DiGiuseppe DL, Christakis DA, Rivara FP. Continuity of binge and harmful drinking from late adolescence to early adulthood. Pediatrics 2004;114:714-9.

45 White KL, Connelly JE, eds. The medical school's mission and the population's health: medical education in Canada, the United Kingdom, the United States, and Australia. Turnberry Isle, FL: Springer Verlag, 1990.

46 Frank E, Elon LK, Hertzberg V. A quantitative assessment of a 4-year intervention that improved patient counseling through improving medical student health. Med Gen Med 2007;9:58.

47 Frank E, Smith D, Fitzmaurice D. A description and qualitative assessment of a 4 year intervention to improve medical student health. Med Gen Med 2005;7:4.

48 Babor TF, Caetano R. Evidence-based alcohol policy in the Americas: strengths, weaknesses, and future challenges. Pan Am J Public Health 2005;18:327-37.

49 Babor TF, Caetano R, Casswell S, Edwards G, Giesbrecht N, Graham K et al. Alcohol: no ordinary commodity: research and public policy. New York: Oxford University Press, 2003.

50 Centers for Disease Control and Prevention. Alcohol. Guide to Community Preventive Services Website, 2008. www. thecommunityguide.org/alcohol/

Accepted: 7 October 2008 